\title{
Antiangiogenic drugs in the management of ocular diseases: Focus on antivascular endothelial growth factor
}

This article was published in the following Dove Press journal:

Clinical Ophthalmology

31 March 2010

Number of times this article has been viewed

\author{
Yukio Sassa \\ Yasuaki Hata \\ Department of Ophthalmology, \\ Graduate School of Medical Sciences, \\ Kyushu University, Fukuoka, Japan
}

\begin{abstract}
Age-related macular degeneration (AMD) complications are the leading cause of severe vision loss among the aging population in the many western countries. The introduction of molecular inhibitors of vascular endothelial growth factor (VEGF), such as pegaptanib, ranibizumab, and bevacizumab, as treatments for wet AMD has provided new hope for affected patients. Now we have these treatment options, which have the possibility to improve or maintain visual acuity for patients suffering from AMD. The treatment needs to be optimized and this is in progress. Based on emerging evidence, adopting a variable VEGF inhibitor-dosing strategy guided by visual acuity assessment and optical coherence tomography are now being tried to reduce the frequency of injections. VEGF inhibitors in combination with photodynamic therapy are another way to optimize treatment. Physicians are waiting for new guidelines for the management of AMD and the results of current and upcoming trials systematically addressing these issues will be expected to provide it.
\end{abstract}

Keywords: age-related macular degeneration, VEGF inhibitor, verteporfin, pegaptanib, ranibizumab, bevacizumab

\section{Age-related macular degeneration and treatment options}

Age-related macular degeneration (AMD) complications are the leading cause of severe vision loss among people aged 65 years and over in the United States ${ }^{1}$ and many western countries. AMD is grouped into two types, dry (nonexudative or nonneovascular) and wet (exudative or neovascular) macular degeneration. About $10 \%-20 \%$ of people with AMD have the wet type, but most (approximately 90\%) of this vision loss is due to neovascular (or wet-type) AMD. ${ }^{2}$ The word 'neovascular' describes the development of new, abnormal blood vessels in the back of the eye. These new abnormal vessels are fragile, and often extravasate blood components, which occasionally becomes subretinal or vitreous bleeding resulting in sudden visual disturbance. Unfortunately, the majority of these new vessels were not amenable to treatment except by laserphotocoagulation including photodynamic therapy, which selectively destroys new abnormal vessels with verteporfin (Visudyne ${ }^{\circledR}$, a light-activated drug) and the use of a low-energy laser.

The Treatment of Age-Related Macular Degeneration with Photodynamic Therapy (TAP) study group revealed that verteporfin therapy for predominantly classic choroidal neovascularization (CNV) subfoveal lesions had benefits for visual acuity without severe adverse effects. ${ }^{3}$ Before the advent of this treatment, treatment options for subfoveal or juxtafoveal CNV, including low-dose radiation therapy, were
3-I-I Maidashi Higashi-ku Fukuoka Japan

Zip 812-8582

Tel $+8 \mathrm{I}-92-642-5648$

Fax +8I-92-642-5663

Email hatachan@med.kyushu-u.ac.jp 
limited and ineffective. In 2000, the US Food and Drug Administration (FDA) approved Visudyne ${ }^{\circledR}$ (new drug application number 21-119) therapy as the first drug treatment for predominantly classic wet-type AMD. Guidelines for verteporfin therapy for choroidal neovascularization secondary to AMD were published in $2002^{4}$ and updated in $2005 .^{5}$ These guidelines were based on trials and clinical experience in predominantly Caucasian populations. The prevalence of AMD is different among racial groups. For example, the leading cause of blindness among white Americans was AMD ( $54.4 \%$ of cases), while among black Americans, cataract and glaucoma accounted for more than $60 \%$ of blindness in the United States. ${ }^{1}$ The leading causes of blindness in a Japanese adult population were glaucoma and diabetic retinopathy. Oxidative damage-induced inflammation initiates AMD. ${ }^{6}$ Macular pigments, which work as antioxidants to prevent oxidative stress from lights, are one of the reasons for the differences in AMD prevalence among racial groups. ${ }^{7}$ More macular pigments are found in the retinas of Asians and blacks compared to retinas in whites. However, results from population-based studies show that the five-year incidence of AMD in Japan was close to those in western countries (Hisayama Study $[0.8 \%],{ }^{8}$ Beaver Dam Eye Study [0.9\%], ${ }^{9}$ Blue Mountain Eye Study $\left.[1.1 \%]^{10}\right)$. Subsequently, the Japanese Age-Related Macular Degeneration Trial (JAT) was designed to evaluate photodynamic therapy for Japanese and found it to be efficacious and safe in Asian patients as well as in Caucasian patients. ${ }^{11}$ In 2004, verteporfin therapy was approved for Japanese patients with wet-type AMD.

The effectiveness of verteporfin therapy depends on the types of AMD in United States. Verteporfin therapy maintained visual acuity for patients with predominantly classic CNV. However, there is insufficient evidence in minimally classic CNV. In Japan, verteporfin therapy was able to maintain visual acuity for at least one year in patients with both types of CNV: predominantly classic and minimally classic lesions. Although this new laser therapy achieved some progress in the treatment for AMD, the effectiveness of this therapy is still limited; it maintained visual acuity, but did not improve it.

Vascular endothelial growth factor (VEGF) is a glycoprotein that stimulates the growth of new blood vessels. This broad term, 'VEGF', covers a number of proteins that result from alternate splicing of mRNA from a single 8-exon $V E G F$ gene. Alternate splicing of exon 6 and 7 alters their amino acid number (in humans: VEGF ${ }_{121}, \mathrm{VEGF}_{145}, \mathrm{VEGF}_{165}, \mathrm{VEGF}_{189}$, $\left.\mathrm{VEGF}_{206}\right)$. Among them, $\mathrm{VEGF}_{121}$ and $\mathrm{VEGF}_{165}$ are mainly expressing in the eye. The results of the VEGF Inhibition
Study in Ocular Neovascularization (VISION) clinical trials in late 2004 marked a new era for the treatment of AMD. This trial tested the concept that targeting VEGF, a potent promoter of angiogenesis, could affect the formation of neovascular vessels in AMD and it was shown to be correct. ${ }^{12}$ They used pegaptanib (Macugen ${ }^{\circledR}$ ), a 28-base ribonucleic acid aptamer, which binds to the $\mathrm{VEGF}_{165}$ isoform with high specificity and affinity but does not bind to the other VEGF isoforms. ${ }^{13}$ This trial clinically proved that anti-VEGF therapy is a promising therapy for the patients with wet-type AMD. Ranibizumab (Lucentis $^{\circledR}$ ) is an antibody fragment that binds and inhibits all identified VEGF isoforms. ${ }^{14}$ Ranibizumab was approved by the FDA in 2006 for the treatment of advanced or wet-type AMD. The approval was based on evidence from clinical trials showing that ranibizumab slows the rate of progression of vision loss from wet AMD. ${ }^{15}$ In addition to a low rate of developing vision loss, approximately one-third of patients treated in these trials had some improvement in vision at 24 months as measured on an eye chart. ${ }^{15}$ The Anti-VEGF Antibody for Treatment of Predominant Classic Choroidal Neovascularization in Age-Related Macular Degeneration (ANCHOR study group) trial revealed that ranibizumab was superior to verteporfin as an intravitreal treatment of predominantly classic CNV. ${ }^{16}$ In this study, ranibizumab improved visual acuity at one year on average. ${ }^{16}$ Bevacizumab (Avastin $^{\mathrm{TM}}$ ) is a drug closely related to ranibizumab. It was approved by the FDA in 2004 as an intravenous treatment for patients with advanced colorectal cancer and therefore has been available for what is called off-label use for other health conditions. It has been widely used to treat wet-type AMD. Bevacizumab is thought to remain in the eye longer than ranibizumab and therefore possibly allows for less frequent injections. No formal dose-ranging or dosing frequency studies have been performed. Almost all of the evidence comes from off-label usage in short-term uncontrolled clinical case series, but the results suggest that is associated with vision stabilization or improvement in most treated eyes. ${ }^{17-20}$

Anti-VEGF therapies were accepted for the treatment of AMD. The first anti-VEGF therapy, pegaptanib, was approved in Europe in 2006 and in Japan in 2008, respectively. This approval was shortly followed by the approval of ranibizumab for the treatment of neovascular AMD in Europe in 2007 and in Japan in 2009, respectively. The outcomes of these new treatments in these countries are forthcoming.

\section{Pegaptanib (Macugen ${ }^{\circledR}$ )}

Pegaptanib $(50 \mathrm{kDa})$ is a specific nucleic acid ligand (aptamer) binding to $\mathrm{VEGF}_{165}$, which plays a critical role in 
angiogenesis and increased permeability. Pegaptanib was licensed in Japan in 2008 for the treatment of neovascular AMD and is administered by intravitreal injection every six weeks for at least two years. ${ }^{21}$

As previously described, the results of the VISION clinical trials in late 2004 marked a new era for the treatment of AMD. These clinical trials revealed the safety and efficacy of pegaptanib for the treatment of neovascular AMD in 1190 patients over two years. ${ }^{12,22,23}$ At baseline, patients were randomized to one of four treatment groups $(0.3 \mathrm{mg}, 1 \mathrm{mg}$, or $3 \mathrm{mg}$ pegaptanib, or sham), with treatment administered every six weeks for 54 weeks (a total of nine treatments). All three doses of pegaptanib were effective in preventing loss of vision compared with sham injections across all CNV subtypes; ${ }^{12} 70 \%$, $71 \%$, and $65 \%$ of patients receiving $0.3 \mathrm{mg}, 1 \mathrm{mg}$, and $3 \mathrm{mg}$ pegaptanib, respectively, experienced a loss of fewer than 15 letters of visual acuity at week 54 compared with $55 \%$ of patients receiving sham injections $(P<0.001, P<0.001$, and $P=0.03$, respectively compared to sham injection). In addition, $33 \%, 37 \%$, and $31 \%$ of patients receiving $0.3 \mathrm{mg}, 1 \mathrm{mg}$, and $3 \mathrm{mg}$ pegaptanib, respectively, maintained their vision or gained vision compared with $23 \%$ of patients receiving sham injections ( $P=0.003, P<0.001$, and $P=0.02$, respectively). After one year of treatment, the sham group was randomized to continuing sham injections, no treatment, or one of the three pegaptanib doses and a follow-up protocol was continued in the next year. As a result, mean visual acuity was maintained in patients receiving $0.3 \mathrm{mg}$ pegaptanib and the proportion of patients losing fewer than 15 letters of visual acuity from week 54 to week $102(7 \%)$ was half that of those who were assigned to two years of sham injections or randomized to stop treatment after one year $(14 \%){ }^{22}$

\section{Complications of intravitreal pegaptanib injection}

The rate of complications in the eye was as follows: endophthalmitis (1.3\%), traumatic injury to the lens $(0.7 \%)$, and retinal detachment $(0.6 \%)$ in the first year and no reports of endophthalmitis or traumatic injury to the lens in the following year. ${ }^{23}$ There was no evidence of an increase in adverse effects associated with systemic VEGF inhibition such as hypertension, thromboembolic events, or serious hemorrhagic events. ${ }^{23}$ An additional one-year systemic safety study confirmed that there was no evidence of systemic VEGF inhibition even at doses up to tenfold the approved $0.3 \mathrm{mg}^{24}$

The VISION clinical trials proved that anti-VEGF therapy is a promising therapy for the patients with wet type AMD, but the outcomes of the next anti-VEGF therapy; ie, ranibizumab, overcame those of pegaptanib therapy in terms of preventing visual loss of the patients with neovascular AMD. Pegaptanib selectively inhibits VEGF $_{165}$ and never inhibits VEGF $_{121}$, while ranibizumab inhibits all identified VEGF isoforms. That is one of the reasons why the ranibizumab therapy is more effective than pegaptanib in preventing loss of vision. In contrast, that reason works well for pegaptanib in terms of the adverse effects. In theory, this selective inhibition reduced the risk of both focal and systemic adverse effects because VEGF also works as a survival signal for cells, including endothelial cells and neural cells. ${ }^{25}$ In addition, pegaptanib is not an antibody and it is poorly immunogenic. Pegaptanib therapy is expected to be used as long-term maintenance therapy after an initial nonselective anti-VEGF therapy including ranibizumab or bevacizumab.

\section{Ranibizumab (Lucentis ${ }^{\circledR}$ )}

Ranibizumab is a humanized monoclonal antibody Fab fragment that inhibits all human isoforms of VEGF-A, and was specifically designed for the treatment of neovascular AMD. Since it is much smaller than the parent molecule, it has the advantage of penetrating to deeper tissues, ie, it is effective in $\mathrm{CNV}$ beneath retinal pigment epithelial cells. In 2009, ranibizumab was licensed for the treatment of neovascular AMD in Japan and is administered by intravitreal injection every four weeks for three months as an initial treatment. The intervals (at least four weeks) after initial treatment are decided according to its effectiveness. ${ }^{26}$

The Minimally Classic/Occult Trial of the Anti-VEGF Antibody to Ranibizumab in the Treatment of Neovascular Age-Related Macular Degeneration (MARINA) study investigated ranibizumab for the treatment of minimally classic or occult with no classic CNV associated with AMD at 96 sites in the United States. ${ }^{15}$ A total of 716 patients were randomized equally to receive 24 monthly intravitreal injections of 0.3 or $0.5 \mathrm{mg}$ ranibizumab, or sham injections. At 24 months, $90 \%$ of patients treated with $0.3 \mathrm{mg}$ ranibizumab and $92 \%$ of those treated with $0.5 \mathrm{mg}$ ranibizumab lost fewer than 15 letters from baseline visual acuity, compared with $52.9 \%$ in the sham-injection group $(P<0.001$ for the comparison of each dose with the sham-injection group). Furthermore, at both 12 and 24 months, approximately one-quarter of patients receiving $0.3 \mathrm{mg}$ ranibizumab and one-third of patients receiving $0.5 \mathrm{mg}$ ranibizumab had gained 15 or more letters in visual acuity, compared with $5.0 \%$ in the sham-injection group at 12 months and $3.8 \%$ at 24 months. Only $0.8 \%$ of patients 
receiving $0.3 \mathrm{mg}$ ranibizumab and $1.2 \%$ of patients receiving $0.5 \mathrm{mg}$ ranibizumab had severe vision loss (lost 30 letters or more of visual acuity), compared with $14.3 \%$ of patients in the sham-injection group.

The ANCHOR group compared ranibizumab with verteporfin photodynamic therapy for the treatment of predominantly classic neovascular AMD. ${ }^{16}$ A total of 423 patients were randomized equally to receive 12 monthly intravitreal injections of 0.3 or $0.5 \mathrm{mg}$ ranibizumab plus sham verteporfin therapy, or monthly sham injections plus active verteporfin therapy. At 12 months, $94.3 \%$ of patients treated with $0.3 \mathrm{mg}$ ranibizumab and $96.4 \%$ of those treated with $0.5 \mathrm{mg}$ ranibizumab lost fewer than 15 letters from baseline visual acuity compared with $64.3 \%$ in the sham-injection group $(P<0.001$ for each comparison). Visual acuity improved by at least 15 letters in $35.7 \%$ and $40.3 \%$ of patients in the $0.3 \mathrm{mg}$ ranibizumab and $0.5 \mathrm{mg}$ ranibizumab treatment groups, respectively, compared with $5.6 \%$ of patients in the verteporfin treatment group ( $P<0.001$ for each comparison).

According to recent large-scale, randomized clinical trials such as MARINA and ANCHOR, the standard regimen of ranibizumab for neovascular AMD is monthly treatments administered for two years. ${ }^{15,16}$ The next trial is to evaluate whether a regimen can be identified that may allow less frequent treatments or visits without compromising visual acuity outcomes. The PIER study (Phase 3b, Multicenter, Randomized, Double-masked, Sham Injection-Controlled Study of the Efficacy and Safety of Ranibizumab in Subjects with Subfoveal Choroidal Neovascularization with or without CNV Secondary to AMD) evaluated ranibizumab administered monthly for three months, followed by injections every four months. ${ }^{27}$ A total of 184 patients were randomized equally to receive three monthly intravitreal injections of 0.3 or $0.5 \mathrm{mg}$ ranibizumab, or sham injections, followed by injections every four months. At 12 months, $83.3 \%$ of patients treated with $0.3 \mathrm{mg}$ ranibizumab and $90.2 \%$ of those treated with $0.5 \mathrm{mg}$ ranibizumab lost fewer than 15 letters from baseline visual acuity, compared with $49.2 \%$ in the sham-injection group $(P<0.001$ for the comparison of each dose with the sham-injection group). However, the improvement in mean visual acuity through month 3 was not sustained to month 12 . The proportion of subjects with substantial improvement by at least 15 letters was not superior to sham treatment. Therefore, more frequent monitoring and dosing may be necessary to identify when treatment is needed.

To address this question, several studies including PRONT $^{28}$ study and SUSTAIN ${ }^{29}$ study were performed to decide whether retreatment is necessary or not by either loss of visual acuity or the retinal thickness evaluated by optical coherence tomography (OCT). Even though PRONT study is very small $(n=40)$ and nonrandomized single - center clinical study, this trial showed the usefulness of OCT to reduce the frequency of injections. A second phase IIIb study $\left(\right.$ SUSTAIN $\left.^{29}\right)$ is evaluated the efficacy of $0.3 \mathrm{mg}$ ranibizumab administered monthly for three consecutive months (loading phase), followed by flexible dosing injection. After receiving three consecutive monthly injections of ranibizumab $0.3 \mathrm{mg}$, patients returned for monthly follow-up and received retreatment with ranibizumab $0.3 \mathrm{mg}$ (or $0.5 \mathrm{mg}$ after it became available) guided by visual acuity assessment and optical coherence tomography (OCT). At the 17th Congress of the European Society of Ophthalmology in Amsterdam, The Netherlands, the outcome of this study was reported as follows: of 531 ranibizumab-naïve patients enrolled in the study, 455 patients reached the 12-month visit. The mean change in patient visual acuity at the end of the loading phase was +5.8 letters, and after 12 months, the improvement was +3.6 letters from baseline. At 12 months, $20.5 \%$ of patients received no additional dose, $16 \%$ required one or two treatments, and $13 \%$ required three or four injections after the loading phase. Although patients still require monthly follow-up, this study suggested the possibility of less frequent treatments to sustain visual acuity acquired after the loading phase.

\section{Complications of intravitreal ranibizumab injection MARINA study}

The rate of complications in the eye for endophthalmitis was $1.0 \%$ (5 of 477 patients) $0.05 \%$ ( 5 of 10,443 injections) in the ranibizumab injection group with none in the shaminjection group. The rate of complications for serious uveitis was $1.3 \%$ (6 of 477 patients) in the ranibizumab injection group with none in the sham-injection group. There was no significant difference between the three treatment groups in the rates of systemic complications. The rates of hypertension (17.2\%, $16.3 \%$, and $16.1 \%$ in the $0.3 \mathrm{mg}$ ranibizumab, $0.5 \mathrm{mg}$ ranibizumab, and sham-injection groups, respectively) and arterial thrombolic events $(4.6 \%, 4.6 \%$, and $3.8 \%$ in the $0.3 \mathrm{mg}$ ranibizumab, $0.5 \mathrm{mg}$ ranibizumab, and shaminjection groups, respectively) were similar across groups at 24 months. Nonocular hemorrhage rates were 9.2\%, 8.8\%, and $5.5 \%$ in the $0.3 \mathrm{mg}$ ranibizumab, $0.5 \mathrm{mg}$ ranibizumab, and sham-injection groups, respectively at 24 months but these differences were not significant. 


\section{ANCHOR study}

The rate of complications in the eye for endophthalmitis was $0.7 \%$ ( 2 of 277 patients) in ranibizumab injection group with none in the verteporfin injection group. The rate of complications for serious uveitis was $0.4 \%$ in the ranibizumab injection group with none in the verteporfin injection group. Interestingly, immunoreactivity to ranibizumab increased in the patients treated with $0.5 \mathrm{mg}$ ranibizumab. Patients with immunoreactivity had more adverse events associated with intraocular inflammation than those without immunoreactivity at any point although the rate of patients with immunoreactivity is small at 12 months $(1.6 \%, 3.9 \%$, and $1.6 \%$ in the $0.3 \mathrm{mg}$ ranibizumab, $0.5 \mathrm{mg}$ ranibizumab, and verteporfin injection groups, respectively). Transient changes in intraocular pressure after injection were common in the ranibizumab injection group. Intraocular pressure over $30 \mathrm{mmHg}$ after injection was more obvious in the ranibizumab injection group at 12 months $(8.8 \%, 8.6 \%$, and $4.2 \%$ in the $0.3 \mathrm{mg}$ ranibizumab, $0.5 \mathrm{mg}$ ranibizumab, and verteporfin injection groups, respectively). There was no significant difference in the rates of arterial thrombolic events between the three treatment groups.

\section{SAILOR study}

An interim safety analysis from the Safety Assessment of Intravitreal Lucentis for AMD (SAILOR) trial indicated a higher incidence of strokes in the $0.5 \mathrm{mg}$ dose group compared with the $0.3 \mathrm{mg}$ dose group ${ }^{30}(1.2 \%$ versus $0.3 \%$, respectively; $P=0.02$ ). Patients with a history of prior stroke appeared to be at higher risk for a subsequent stroke.

\section{Bevacizumab (Avastin ${ }^{\mathrm{TM}}$ )}

Since bevacizumab was available prior to the launch of ranibizumab, bevacizumab is the most commonly used medication in the eye. This molecule has two antigen-binding domains (ranibizumab has one). Only a limited number of studies of bevacizumab have evaluated acute retinal toxicity in animals, and no toxicity has been identified. No formal dose-ranging or dosing-frequency studies have been performed. Bevacizumab is associated with vision stabilization or improvement in most treated eyes and simultaneous improvements in OCT and fluorescein angiographic markers of disease activity. ${ }^{17-20}$

In Europe, bevacizumab is currently approved for the treatment of colorectal cancer and advanced or metastatic renal cell cancer, and has been also used on off-label basis for the treatment of AMD. ${ }^{31,32}$ Several trials demonstrated that bevacizumab achieved a level of success for the treatment of AMD without severe adverse effects in Europe. ${ }^{31,32}$ In the
United Kingdom, the National Health Service is running a multicenter clinical trial, IVAN (Inhibit VEGF in Age-related choroidal Neovascularization) study, to compare safety and efficacy of ranibizumab and bevacizumab for the treatment of neovascular AMD.

\section{Intravitreal bevacizumab in combination with verteporfin photodynamic therapy}

In Japan, bevacizumab has been used for eye diseases since 2005. To the best of our knowledge, there are few reports about the outcomes of intravitreal bevacizumab for Asian patients with AMD. ${ }^{33-35}$ One report from Japan demonstrated that combined photodynamic therapy and intravitreal bevacizumab injection reduced the height of retinal pigment epithelial detachment secondary to AMD evaluated by OCT and stabilized visual acuity at one year. ${ }^{29}$ In this report, two eyes in 22 cases $(9 \%)$ had decreased vision due to a retinal pigment epithelial tear and subretinal hemorrhage.

\section{Complications of intravitreal bevacizumab injection}

In Japan, Iizima and colleagues surveyed the use of bevacizumab in 106 hospitals, where verteporfin therapy was administered to AMD patients. ${ }^{36}$ Although this article was published in Japanese, the survey of the use and safety of intravitreal bevacizumab injections in Asian patients is valuable. In this article, bevacizumab was used for diseases such as AMD, polypoidal choroidal vasculopathy, retinal angiomatous proliferation, myopic choroidal neovascular vessels, CNV in angioid streaks, macular edema in nonischemic branch/central retinal vein occlusion, and diabetic maculopathy. Bevacizumab was used at the dose of 1.25 $\mathrm{mg} / 0.05 \mathrm{~mL}$ for single injection in almost all hospitals (93\%). There were 21,328 injections in total in this trial. The rate of complications in the eye was as follows: endophthalmitis $(0.04 \%)$, retinal detachment $(0.03 \%)$, retinal hemorrhages after injection $(0.06 \%)$, traumatic injury to the lens $(0.06 \%)$, retinal pigment epithelial tears $(0.15 \%)$, uveitis $(0.03 \%)$, elevated intraocular pressure $(0.01 \%)$, retinal breaks $(0.02 \%)$, and acute visual loss without apparent reasons $(0.05 \%)$. Retinal artery occlusion was observed only in one case. The rate of systemic complications was as follows: cerebral infarction $(0.06 \%)$, menstrual irregularity $(0.05 \%)$, and cutaneous change $(0.02 \%)$. Elevated blood pressure was observed in only one case.

Fung and colleagues reported complications in patients after intravitreal bevacizumab injection. ${ }^{37}$ In this trial, there were 7,113 injections in total that were complicated 
by endophthalmitis $(0.01 \%)$, retinal detachment $(0.04 \%)$, traumatic injury to the lens $(0.01 \%)$, retinal pigment epithelial tears $(0.06 \%)$, subretinal bleeding $(0.06 \%)$, uveitis $(0.14 \%)$, elevated intraocular pressure $(0.01 \%)$, retinal artery occlusion $(0.01 \%)$, and acute visual loss without apparent reason $(0.07 \%)$. Systemic complications were cerebral infarction $(0.07 \%)$ and elevated blood pressure $(0.21 \%)$.

The rate of complications presented above appears to be lower than those from the MARINA or VISION clinical trials since the rates were calculated by the number of total injections in our two trials (Iizima and Fung), while the rates were calculated by the number of total patients in the MARINA or VISION trials. Shima and colleagues reported the rate of complications per patient (total 707 patients) within two month after intravitreal injection of bevacizumab ${ }^{38}$ were endophthalmitis $(0.28 \%)$, traumatic injury to the lens $(0.14 \%)$, retinal pigment epithelial tears $(0.14 \%)$, uveitis $(0.28 \%)$, and acute visual loss without apparent reason $(0.28 \%)$. Systemic complications were cerebral infarction $(0.14 \%)$, menstrual irregularity $(0.42 \%)$, cutaneous change $(0.28 \%)$, and elevated blood pressure $(0.28 \%)$.

Cerebral infarction is one of the more severe complications after intravenous injection of bevacizumab combined with other anticancer agents for the treatment of colorectal cancer. However, it is difficult to determine whether stroke is caused by chemotherapy or cancer itself, because some tumors are at high risk for cerebrovascular complications. ${ }^{39}$ Since VEGF stimulates the synthesis of endothelial nitric oxide synthase and prostacyclin in endothelial cells, ${ }^{40-42}$ anti-VEGF drugs may inhibit these properties and result in vascular occlusions, including cerebral infarction and retinal artery occlusions.

\section{Ranibizumab vs bevacizumab: What's the difference?}

Ranibizumab and bevacizumab are produced by the same company, Genentech Inc. (San Francisco, CA), a leader in research and product development in the area of angiogenesis. Ranibizumab (formerly known as rhuFAb V2) is an antibody fragment that binds and inhibits all identified VEGF isoforms, while bevacizumab is a recombinant, humanized, monoclonal immunoglobulin G1 antibody that also binds to and inhibits all isoforms of human VEGF. ${ }^{17,42}$ In targeting VEGF, these two drugs are similar. What is the difference? Since ranibizumab $(48.3 \mathrm{kDa})$ is an antibody fragment, its molecular weight is much smaller than bevacizumab (149 $\mathrm{kDa})$. Preclinical studies suggested that a full-length antibody would not penetrate all layers of the retina (approximately $76.5 \mathrm{kDa}){ }^{44}$ This is why ranibizumab was designed specifically to treat neovascular AMD by manipulating the structure of the murine monoclonal antibody from which bevacizumab was derived. After clinical evidence of a treatment effect of the full-length antibody (bevacizumab) in humans, additional animal studies have found that this particular full-length antibody can penetrate all retinal layers. ${ }^{17}$

The problem with ranibizumab is its cost. A single dose of the drug costs more than $\$ 2,000$, whereas a single injectable dose of bevacizumab costs about $\$ 50$ in United States. Even the typical Medicare copayment of $20 \%$, or US\$400, is more than twice as costly as the full price of an injection of bevacizumab. In Japan, the cost of a single dose of ranibizumab is $¥ 170,000$ (approximately US\$1700), while bevacizumab is $¥ 1000$ (approximately US\$10). In line with the effects of the aging population in developed countries, the annual costs of health care are increasing rapidly. If bevacizumab works as an AMD treatment as well as ranibizumab with similar rates of serious adverse events, bevacizumab may be a better treatment for AMD. In February 2008, the National Eye Institute of the National Institutes of Health started a multicenter clinical trial to compare the relative safety and effectiveness of these two drugs, the Comparison of AMD Treatments Trials (CATT): Lucentis-Avastin Trial. In this trial, 1,200 patients with wet-type AMD will be treated with either:

1. Injection of Lucentis on a fixed schedule of once every four weeks for one year. The patient is assigned randomly in the second year to either an injection of Lucentis every four weeks or on a variable schedule depending on the patient's response to treatment;

2. Injection of Avastin on a fixed schedule of once every four weeks for one year. The patient is assigned randomly in the second year to either an injection of Avastin every four weeks or on a variable schedule depending on the patient's response to treatment;

3. Injection of Lucentis on a variable schedule;

4. Injection of Avastin on a variable schedule.

Evaluating points are visual acuity, number of treatments, anatomical changes in the retina, adverse events, and cost. This clinical trial is being conducted at 47 clinical centers in the US. It is hoped the results of this study will improve the treatment of wet-type AMD. Reducing the frequency of treatments without compromising effectiveness would reduce the treatment burden for patients and produce potential cost savings. 
For the same purpose as the CATT study, many studies including IVAN (UK), MANTA (Austria), VIBERA (Germany), LUCAS (Norway), GEFAL (France) and FIGDAME (Spain) are working in the way.

\section{Is off-label use of drugs legal?}

The FDA-labeled indication of bevacizumab is for the treatment of colon cancer. Its use in the eye is therefore off-label; no solid data exists on its safety and efficacy. Is off-label use of drugs legal? Off-label use of drugs is not illegal. It is not uncommon to use off-label use of drugs including triamcinolone acetonide ${ }^{45}$ and tissue plasminogen activators ${ }^{46}$ for intravitreal injection. In terms of triamcinolone, Tano and Machemer originally reported that intravitreal injection of triamcinolone was effective to proliferative vitreoretinal diseases with an experimental proliferative vitreoretinopathy model. ${ }^{47}$ Several reports demonstrated that intravitreal injection of triamcinolone is effective in retinal disease such as retinal leakage ${ }^{48}$ and subretinal neovasculation ${ }^{49}$ in animal models. Machemer's group reported that intravitreal injection of triamcinolone did not have retinal toxicity in rabbits with electrophysiological and morphological methods. ${ }^{50}$ Fifteen years later in Australia, triamcinolone was intravitreally administered off-label. ${ }^{45}$ Fortunately, this pilot study reported that intravitreal injection for exudative AMD improved visual acuity without severe adverse effects. ${ }^{45}$ These reports encourage the use of triamcinolone for vitreoretinal disease even in off-label use. Several clinical studies support its effectiveness and now intravitreal injection of triamcinolone for vitreoretinal disease is widespread. Likewise, use of bevacizumab is now the most commonly used anti-VEGF drug in the eye. Although preclinical studies have almost exclusively found bevacizumab to be safe, the design utilized in clinical case series cannot rule out a possible increase in adverse events. We should keep in mind that common practice does not make the use of bevacizumab safe. There may be a risk of unexpected adverse outcomes, but this is also true of labeled use of new drugs. Some adverse effects do not become apparent until after several years of use and thousands of prescriptions.

\section{Treatment possibility for other diseases besides AMD}

We now know VEGF-targeting pharmacotherapy works well for wet-type AMD, but VEGF is active in other eye diseases including diabetic macular edema (DME), retinal vascular thrombosis, neovascular glaucoma, and CNV resulting from other causes such as high myopia or angioid streaks. Several reports are now showing the effectiveness and safety of VEGF-targeting pharmacotherapy in these diseases. For retinal vascular occlusions (RVO), phase III trials (the CRUISE study for CRVO and the BRAVO study for BRVO) are now under way. The NVG study (Lucentis for New Onset Neovascular Glaucoma) will show us the efficacy and safety of lucentis treatment for neovascular glaucoma. DME is the second best-researched disease in treatment with VEGF-targeting pharmacotherapy. Two phase II trials (READ2 ${ }^{51}$ and RESOLVE) suggest a benefit for ranibizumab in the treatment of DME. At the 2008 Joint Meeting of the American Academy of Ophthalmology and the European Society of Ophthalmology, the outcome of the RESOLVE study was reported. In this study, subjects were randomized to receive 3 monthly injections with either 0.3 or $0.5 \mathrm{mg}$ ranibizumab or placebo (sham group). Treatment was then administered on an as-needed basis, depending on response to initial treatment. The dose of ranibizumab increased doubled after 1 month if edema resolution was incomplete. This use of a higher dose after 1 month was quite different from the way of the treatment for AMD, mainly because the VEGF levels in active diabetic retinopathy are higher than in AMD. Photocoagulation after 3 injections was given if needed. In this trial, ranibizumab was superior to placebo with respect to changes in BCVA letter score and central retinal thickness. The safety profile of ranibizumab was comparable to that observed in patients with AMD. Phase III trials (RISE and RIDE) are now underway to evaluate the efficacy of ranibizumab in DME.

\section{Conclusion}

Although the prevalence of AMD in Japan is lower than those in western countries, the number of patients suffering from AMD is increasing as the Japanese shift from their traditional diet to a fatty, high calorie western diet. In the 1990's, treatment options for wet-type AMD were limited and ineffective. Now we have several treatment options, which have the possibility to improve or maintain visual acuity for patients suffering from AMD. The treatment now needs to be optimized and this is in progress. Several clinical trials are now running, including the CATT trial, combination therapy with photodynamic therapy, anti-VEGF drugs, and triamcinolone acetonide. However, even in patients with wettype AMD, there are patients left behind from large-scale, randomized clinical trials such as MARINA and ANCHOR. Predominantly blood or scar lesions were not included in those two trials. We have no treatment options available for 
these patients. New approaches for these types of CNV must be developed.

\section{Future options}

In the experimental reports, there are several new pharmacotherapies for AMD besides those described above. Even if we focus on similar mechanisms, ie, anti-VEGF drugs, several pharmacotherapies are now into phase III clinical trials.

Bevasiranib (Opko Health, Miami, FL) is a first-in-class small interfering RNA drug designed to silence the genes that produce VEGF. The phase III COBALT clinical trial will evaluate whether bevasiranib administered every eight or 12 weeks is as effective as ranibizumab administered every four weeks for preventing vision loss. Its effectiveness in maintenance therapy after initiation with three doses of ranibizumab is also under investigation.

VEGF Trap-Eye (Bayer HealthCare, Pittsburgh, PA; Regeneron, Tarrytown, NY) is a human soluble VEGF receptor fusion protein that binds all types of VEGF-A as well as the related placental growth factor. One arm of the phase III VIEW studies is enrolling a cohort to be treated with $2 \mathrm{mg}$ of VEGF Trap-Eye every eight weeks compared with every four weeks.

\section{Disclosures}

The authors report no conflicts of interest in this work.

\section{References}

1. The Eye Diseases Prevalence Research Group. Causes and prevalence of visual impairment among adults in the United States. Arch Ophthalmol. 2004; 122:477-485.

2. Ferris FL III, Fine SL, Hyman L. Age-related macular degeneration and blindness due to neovascular maculopathy. Arch Ophthalmol. 1984;102:1640-1642.

3. Bressler NM; Treatment of Age-Related Macular Degeneration with Photodynamic Therapy (TAP) Study Group. Photodynamic therapy of subfoveal choroidal neovascularization in age-related macular degeneration with verteporfin: two-year results of 2 randomized clinical trials-tap report 2. Arch Ophthalmol. 2001;119:198-207.

4. Verteporfin Roundtable 2000 and 2001 Participants; Treatment of age-related macular degeneration with photodynamic therapy (TAP) study group principal investigators; Verteporfin in photodynamic therapy (VIP) study group principal investigators. Guidelines for using verteporfin (Visudyne) in photodynamic therapy to treat choroidal neovascularization due to age-related macular degeneration and other causes. Retina. 2002;22:6-18.

5. Verteporfin Roundtable Participants. Guidelines for using verteporfin (Visudyne) in photodynamic therapy for choroidal neovascularization due to age-related macular degeneration and other causes: update. Retina. 2005;25:119-134.

6. Hollyfield JG, Bonilha VL, Rayborn ME, et al. Oxidative damageinduced inflammation initiates age-related macular degeneration. Nat Med. 2008;14:194-198.

7. Beatty S, Koh H, Phil M, Henson D, Boulton M. The role of oxidative stress in the pathogenesis of age-related macular degeneration. Surv Ophthalmol. 2000;45:115-134.
8. Miyazaki M, Kiyohara Y, Yoshida A, Iida M, Nose Y, Ishibashi T. The 5-year incidence and risk factors for age-related maculopathy in a general Japanese population: the Hisayama study. Invest Ophthalmol Vis Sci. 2005;46:1907-1910.

9. Klein R, Klein BE, Jensen SC, Meuer SM. The five-year incidence and progression of age-related maculopathy: the Beaver Dam Eye Study. Ophthalmology. 1997;104:7-21.

10. Mitchell P, Wang JJ, Foran S, Smith W. Five-year incidence of age-related maculopathy lesions: the Blue Mountains Eye Study. Ophthalmology. 2002;109:1092-1097.

11. Japanese Age-Related Macular Degeneration Trial (JAT) Study Group. Japanese age-related macular degeneration trial: 1-year results of photodynamic therapy with verteporfin in Japanese patients with subfoveal choroidal neovascularization secondary to age-related macular degeneration. Am J Ophthalmol. 2003;136: 1049-1061.

12. Gragoudas ES, Adamis AP, Cunningham ET Jr, Feinsod M, Guyer DR; VEGF Inhibition Study in Ocular Neovascularization Clinical Trial Group. Pegaptanib for neovascular age-related macular degeneration. N Engl J Med. 2004;351:2805-2816.

13. Eyetech Study Group. Preclinical and phase $1 \mathrm{~A}$ clinical evaluation of an anti-VEGF pegylated aptamer (EYE001) for the treatment of exudative age-related macular degeneration. Retina. 2002;22:143-152.

14. Gaudreault J, Fei D, Rusit J, Suboc P, Shiu V. Preclinical pharmacokinetics of Ranibizumab (rhuFabV2) after a single intravitreal administration. Invest Ophthalmol Vis Sci. 2005;46:726-733.

15. Rosenfeld PJ, Brown DM, Heier JS, et al; MARINA Study Group. Ranibizumab for neovascular age-related macular degeneration. $N E n g l$ J Med. 2006;355:1419-1431.

16. Brown DM, Kaiser PK, Michels M, et al; ANCHOR Study Group. Ranibizumab versus verteporfin for neovascular age-related macular degeneration. N Engl J Med. 2006;355:1432-1444.

17. Avery RL, Pieramici DJ, Rabena MD, Castellarin AA, Nasir MA, Giust MJ. Intravitreal bevacizumab (Avastin) for neovascular age-related macular degeneration. Ophthalmology. 2006;113: 363-372.

18. Bashshur ZF, Bazarbachi A, Schakal A, Haddad ZA, El Haibi CP, Noureddin BN. Intravitreal bevacizumab for the management of choroidal neovascularization in age-related macular degeneration. Am J Ophthalmol. 2006;142:1-9.

19. Rich RM, Rosenfeld PJ, Puliafito CA, et al. Short-term safety and efficacy of intravitreal bevacizumab (Avastin) for neovascular age-related macular degeneration. Retina. 2006;26:495-511.

20. Emerson MV, Lauer AK, Flaxel CJ, et al. Intravitreal bevacizumab (Avastin) treatment of neovascular age-related macular degeneration. Retina. 2007;27:439-444.

21. Eyetech Inc., Pfizer Inc. Macugen (pegaptanib sodium injection) prescribing information. New York, NY: Eyetech Inc; 2006.

22. Chakravarthy U, Adamis AP, Cunningham ET Jr, et al. Year 2 efficacy results of 2 randomized controlled clinical trials of pegaptanib for neovascular age-related macular degeneration. Ophthalmology. 2006;113:1508-1525.

23. D'Amico DJ, Masonson HN, Patel M, et al. Pegaptanib sodium for neovascular age-related macular degeneration: two-year safety results of the two prospective, multicenter, controlled clinical trials. Ophthalmology. 2006;113:992-1001.

24. Apte RS, Modi M, Masonson H, Patel M, Whitfield L, Adamis AP. Pegaptanib 1-year systemic safety results from a safety-pharmacokinetic trial in patients with neovascular age-related macular degeneration. Ophthalmology. 2007;114:1702-1712.

25. Zachary I. Neuroprotective role of vascular endothelial growth factor: signalling mechanisms, biological function, and therapeutic potential. Neurosignals. 2005;14:207-221.

26. Genentech Inc., Novartis Inc. Lucentis solution for intravitreal injection (ranibizumab (Genetical Recombination)) prescribing information. San Francisco, CA: Genentech Inc.; 2008. 
27. Regillo CD, Brown DM, Abraham P, et al. Randomized, double masked, sham-controlled trial of ranibizumab for neovascular agerelated macular degeneration: PIER Study Year 1. Am J Ophthalmol. 2008;145:239-248.

28. Fung AE, Lalwani GA, Rosenfeld PJ, et al. An optical coherence tomography-guided, variable dosing regimen with intravitreal ranibizumab (Lucentis) for neovascular age-related macular degeneration. Am J Ophthalmol. 2007;143:566-583.

29. Meyer CH, Eter N, Holz FG, et al. Ranibizumab in patients with subfoveal choroidal neovascularization secondary to age-related macular degeneration. Interim results from the SUSTAIN Trial [abstract]. Invest Ophthalmol Vis Sci. 2008;49:273.

30. Genentech Inc. "Dear Doctor" letter. January 24, 2007. Available at:http://www.gene.com/gene/products/information/pdf/healthcareprovider-letter.pdf. Accessed September 27, 2008.

31. Aisenbrey S, Ziemssen F, Volker M, et al. Intravitreal bevacizumab (Avastin) for occult choroidal neovascularization in age-related macular degeneration. Graefes Arch Clin Exp Ophthalmol. 2007;245: 941-948.

32. Fong KC, Kirkpatrick N, Mohamed Q, Johnston RL. Intravitreal bevacizumab (Avastin) for neovascular age-related macular degeneration using a variable frequency regimen in eyes with no previous treatment. Clin Experiment Ophthalmol. 2008;36:748-755.

33. Shima C, Gomi F, Sawa M, Sakaguchi H, Tsujikawa M, Tano Y. One-year results of combined photodynamic therapy and intravitreal bevacizumab injection for retinal pigment epithelial detachment secondary to agerelated macular degeneration. Graefes Arch Clin Exp Ophthalmol. 2009;247:899-906.

34. Roh MI, Kim HS, Song JH, Lim JB, Koh HJ, Kwon OW. Concentration of cytokines in the aqueous humor of patients with naive, recurrent and regressed CNV associated with AMD after bevacizumab treatment. Retina. 2009;29:523-529.

35. Liu Y, Wen F, Li J, Zuo C, Li M. Transitions of multifocal electroretinography in patients with age-related macular degeneration after combination therapy with photodynamic therapy and intravitreal bevacizumab. Doc Ophthalmol. 2009 Aug 15. [Epub ahead of print].

36. Iizima H, Imazawa M, Satoh T, Nagai Y. Nationwide survey of intravitreal bevacizumab. Ganka. 2009;51:927-933.

37. Fung AE, Rosenfeld PJ, Reichel E. The International Intravitreal Bevacizumab Safety Survey: using the internet to assess drug safety worldwide. Br J Ophthalmol. 2006;90:1344-1349.

38. Shima C, Sakaguchi H, Gomi F, et al. Complications in patients after intravitreal injection of bevacizumab. Acta Ophthalmol. 2008;86: $372-376$
39. Saynak M, Cosar-Alas R, Yurut-Caloglu V, Caloglu M, Kocak Z, Uzal C. Chemotherapy and cerebrovascular disease. J BUON. 2008;13: 31-36.

40. Kroll J, Waltenberger J. VEGF-A induces expression of eNOS and iNOS in endothelial cells via VEGF receptor-2 (KDR). Biochem Biophys Res Commun. 1998;252:743-746.

41. Murohara T, Horowitz JR, Silver M, et al. Vascular endothelial growth factor/vascular permeability factor enhances vascular permeability via nitric oxide and prostacyclin. Circulation. 1998;97:99-107.

42. Hata Y, Clermont A, Yamauchi T, et al. Retinal expression, regulation, and functional bioactivity of prostacyclin-stimulating factor. J Clin Invest. 2000;106:541-550.

43. Gaudreault J, Fei D, Rusit J, Suboc P, Shiu V. Preclinical pharmacokinetics of Ranibizumab (rhuFabV2) after a single intravitreal administration. Invest Ophthalmol Vis Sci. 2005;46:726-733.

44. Jackson TL, Antcliff RJ, Hillenkamp J, Marshall J. Human retinal molecular weight exclusion limit and estimate of species variation. Invest Ophthalmol Vis Sci. 2003;44:2141-2146.

45. Penfold PL, Gyory JF, Hunyor AB, Billson FA. Exudative macular degeneration and intravitreal triamcinolone. A pilot study. Aust $N Z J$ Ophthalmol. 1995;23:293-298.

46. Hesse L, Kroll P. Successful treatment of acute subretinal hemorrhage in age-related macular degeneration by combined intravitreal injection of recombinant tissue plasminogen activator and gas. Adv Ther 1997; 14:275-280.

47. Tano Y, Chandler D, Machemer R. Treatment of intraocular proliferation with intravitreal injection of triamcinolone acetonide. Am JOphthalmol. 1980;90:810-816.

48. Wilson CA, Berkowitz BA, Sato Y, Ando N, Handa JT, de Juan E Jr. Treatment with intravitreal steroid reduces blood-retinal barrier breakdown due to retinal photocoagulation. Arch Ophthalmol. 1992;110:1155-1159.

49. Ishibashi T, Miki K, Sorgente N, Patterson R, Ryan SJ. Effects of intravitreal administration of steroids on experimental subretinal neovascularization in the subhuman primate. Arch Ophthalmol. 1985;103:708-711.

50. McCuen BW 2nd, Bessler M, Tano Y, Chandler D, Machemer R. The lack of toxicity of intravitreally administered triamcinolone acetonide. Am J Ophthalmol. 1981;91:785-788.

51. Nguyen QD, Shah SM, Heier JS, et al. READ-2 Study Group. Primary End Point (Six Months) Results of the Ranibizumab for Edema of the mAcula in diabetes (READ-2) study. Ophthalmology. 2009;116: 2175-2181.
Clinical Ophthalmology

\section{Publish your work in this journal}

Clinical Ophthalmology is an international, peer-reviewed journal covering all subspecialties within ophthalmology. Key topics include: Optometry; Visual science; Pharmacology and drug therapy in eye diseases; Basic Sciences; Primary and Secondary eye care; Patient Safety and Quality of Care Improvements. This journal is indexed on

\section{Dovepress}

PubMed Central and CAS, and is the official journal of The Society of Clinical Ophthalmology (SCO). The manuscript management system is completely online and includes a very quick and fair peer-review system, which is all easy to use. Visit http://www.dovepress.com/ testimonials.php to read real quotes from published authors. 